\title{
ARTERIAL-VENTRICULAR COUPLING IN PRETERMS WITH PATENT DUCTUS
} ARTERIOSUS

\author{
V.J. Jeitler ${ }^{1}$, S. Baumgartner ${ }^{1}$, M. Wald ${ }^{1}$, T. Waldhör ${ }^{2}$, U. Salzer-Muhar ${ }^{3}$
}

${ }^{I}$ Division of Paediatric Neonatology, Intensive Care and Neuropaediatry, Department of Pediatrics and Adolescent Medicine, ${ }^{2}$ Department of Epidemiology, ${ }^{3}$ Division of Paediatric Cardiology, Department of Pediatrics and Adolescent Medicine, Medical University of Vienna, Vienna, Austria

Aim of the study: To analyze arterial-ventricular coupling (AV-C) in a cohort of preterms before and after ductal closure.Patients and methods.

Inclusion criteria: Gestational age $<33+0$, normal intracardiac anatomy, no coarctation, minimum stay in the NICU from day 1 to day 3 of life in the period from 11/2009 - 11/2010. Further criteria were complete M-mode (left atrium, left ventricle) and Doppler recordings (left pulmonary artery, descending aorta and PDA), Patients were stratified into 4 subgroups according to GA. PDA flow patterns were classified according to Skinner (PDA type 1-6). As a measure for AV-C the ratio of effective arterial elastance to leftventricular endsystolic elastance $\left(\mathrm{E}_{\mathrm{A}} / \mathrm{E}_{\mathrm{LV}}\right)$ was calculated based on $\mathrm{M}$-mode derived volumes.

Results: The study cohort comprised of 79 patients (subgroup 1 (GA23+0-24+6) $n=17$, subgroup 2 (GA $25+0-26+6) n=29$, subgroup 3 (GA 27+0-28+6) $n=21$, subgroup 4 GA29+0 $-32+6) n=12$ ). PDA types 5 and 6 were found in $41 \%, 28 \%, 24 \%$ and $8 \%$ of patients in subgroups $1,2,3$, and 4 respectively. $67 / 79$ patients with a PDA type 3-6 received ibuprofen, in 12 of them ductal clipping was required. Calculation of $\mathrm{E}_{\mathrm{A}} / \mathrm{E}_{\mathrm{LV}}$ before and after ductal closure revealed the following ratios: Subgroup 1: 0.28 vs. 0.27, subgroup 2: 0.31 vs.0.35, subgroup 3: 0.45 vs. 0.39 and subgroup 4: 0.51 vs. 0.33 .

Conclusion: Our preliminary data indicate that the effect of ductal closure on either $\mathrm{E}_{\mathrm{A}}$ or $\mathrm{E}_{\mathrm{LV}}$ or both depends on gestational age. 